Формирование профессиональноценностных ориентаций будущих психологов служебной деятельности на этапе профессиональной подготовки в вузе

Орлова Е.А. ${ }^{1, a}$, Гребенников Ю.Л.,

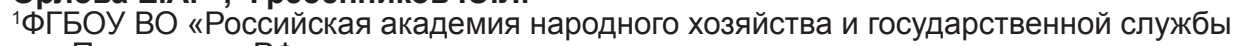
при Президенте РФ»,

Москва, Российская Федерация.

2ГОУ ВО МО «Московский государственный областной университет»,

Мытищи, Московская область, Российская Федерация.

a ID ORCID: https://orcid.org/0000-0002-4517-3955, e-mail: orlova.elena64@yandex.ru

b (iD ORCID: https://orcid.org/0000-0003-3868-6979, e-mail: imaruel@gmail.com

Аннотация: Цель статьи - теоретическое осмысление проблемы формирования профессионально-ценностных ориентаций будущих психологов служебной деятельности на этапе вузовского обучения. Вероятно, сами эти фракторы можно считать «одинаковыми» для всех вузов, однако, цели и задачи подготовки специалистов, содержание образовательных программ в «ведомственных» и «гражданских» вузах будут различаться, задавая «вектор» личностно-професионального становления обучающихся.

Методы-теоретический анализ и обобщение подходов к рассмотрению данной проблемы.

Показано, что профессионально-ценностные ориентации (ПЦО) понимаются в современной психологической литературе как интегративная личностная структура, определяющая профессиональное сознание специалиста, характеризующая его отношение к профессии, отражающая содержательную сторону направленности личности на ценности профессиональной деятельности, в том числе - в аспекте ценности образования и профессии. В структуре ПЦО выделяют когнитивный, эмоциональный и поведенческий компонент, при этом содержательные особенности ПЦО будущего психолога служебной деятельности могут выявляться через изучение профессиональных установок, профессиональных мотивов и профессиональных ценностей. Основными фрункциями ПЦО являются смыслообразующая, оценочно-регулятивная и социально-ориентирующая.

В результате исследования разработана модель изучения и формирования профессионально-ценностных ориентаций будущих психологов служебной деятельности, которая может быть положена в основу как эмпирического исследования, так и рекомендаций по формированию и коррекции профессионально-ценностных ориентаций будущих психологов служебной деятельности в разных условиях обучения.

Ключевые слова: служебная деятельность, профессионально-ценностные ориентации, психолог в сфере служебной деятельности.

Для цитирования: Орлова Е.А. Формирование профессионально-ценностных ориентаций будущих психологов служебной деятельности на этапе профессиональной подготовки в вузе / Е.А. Орлова, Ю.Л. Гребенников // Развитие обрзования. - 2021. - T. 4, №3. - C. 39-45. DOI 10.31483/r-99347.

\title{
Formation of Professional and Value Orientations of Future Psychologists of Professional Activity at the Stage of Professional Training at the University
}

\author{
Elena A. Orlova1,a, Yulia L. Grebennikov2,b
} ${ }^{1}$ FSBEI of HE "The Russian Presidential Academy of National Economy and Public Administration", Moscow, Russian Federation.

${ }^{2}$ SEI of HE of MR "Moscow State Regional University", Mytishchi, Moscow Region, Russian Federation. DORCID: https://orcid.org/0000-0002-4517-3955, e-mail: orlova.elena64@yandex.ru b iD ORCID: https://orcid.org/0000-0003-3868-6979, e-mail: imaruel@gmail.com

\begin{abstract}
The purpose of the article is a theoretical understanding of the problem of the formation of professional and value orientations of future psychologists of professional activity at the stage of university training. Probably, these factors themselves can be considered «the same» for all universities, however, the goals and objectives of training specialists, the content of educational programs in «departmental» and «civil» universities will differ, setting the «vector» of personal and professional formation of students.

Methods - theoretical analysis and generalization of approaches to the consideration of this problem.

It is shown that professional value orientations are understood in modern psychological literature as an integrative personal structure that determines the professional consciousness of a specialist, characterizes his attitude to the profession, reflects the content side of the personality's orientation to the values of professional activity, including in the aspect of the value of education and profession. The cognitive, emotional and behavioral components are distinguished in the structure of the PCE, while the content features of the PCE of the future psychologist of professional activity can be revealed through the study of professional attitudes, professional motives and professional values. The main functions of the PCE are semantic, evaluative-regulatory and socially-oriented.

As a result of the study the model for studying and forming professional value orientations of future psychologists of professional activity, which can be used as the basis for both empirical research and recommendations for the formation and correction of professional value orientations of future psychologists of professional activity in different training conditions has been developed.

Keywords: professional activity, professional and value orientations, a psychologist in the field of official activity.

For citation: Orlova E.A., \& Grebennikov Y.L. (2021). Formation of Professional and Value Orientations of Future Psychologists of Professional Activity at the Stage of Professional Training at the University. Razvitie obrazovaniya =
\end{abstract} Development of education, 4(3), 39-45. (In Russ.) DOI 10.31483/r-99347. 


\title{
Хӗсмет ӗс̧ӗн пулас психологӗсен профрессипе пӗлтерӗшлӗх ориентацийӗ аслӑ шкул тапхӑрӗнче йӗркеленни
}

\author{
Орлова Е.А. ${ }^{1, a}$, Гребенников Ю.Л., \\ ${ }^{1} \mathrm{AB}$ «Халӑх хус̧алӑхӗпе патшалӑх службин РФ Президенчӗ с̧умӗнче ӗс̧лекен Рас̧с̧ей академийӗ» \\ ФПБВУ, \\ Мускав, Рас̧с̧ей Федерацийӗ. \\ ${ }^{2} \mathrm{BM} \mathrm{AB} \mathrm{«Мускав} \mathrm{патшалӑх} \mathrm{область} \mathrm{университечӗ»} \mathrm{ПВУ,}$ \\ Мытищи, Мускав облас̧ӗ, Рас̧с̧ей Федерацийӗ. \\ a iD ORCID: https://orcid.org/0000-0002-4517-3955, e-mail: orlova.elena64@yandex.ru \\ b (iD ORCID: https://orcid.org/0000-0003-3868-6979, e-mail: imaruel@gmail.com
}

Аннотаци: Статьян тӗллевӗ - хӗсмет ӗс̧ӗн пулас психологӗсен профессипе пахалӑх ориентацийӗ аслӑ шкул тапхӑрӗнче йӗркеленнин йывӑр ыйтӑвӗсене теори шайӗнче тишкересси. Ку ыйтусем кашниех малтанласа пире пӗрешкел пек туйӑнас̧с̧ӗ пуль, анчах специалистсене хатӗрлессин тӗллевӗсемпе задачисем, вӗренӱ програмисен содержанийӗ, «ведомство» тата «граждан» вузӗсенче, вӗренекенсем професси с̧ул-йӗрне хайсем витӗм кӱнине пула пӗр-пӗринчен уйрӑлса тӑрас̧сеӗ.

Меслетсем - панӑ проблемӑна пӑхса тухмалли расна с̧ул-йӗре тишкерсе пӗтӗмлетӱ туни.

Ак мӗн кӑтартса панӑ: професси пӗлтерӗшне тӗрӗс хаклас ориентацие (ППО) хальхи психологи литературинче с̧ыннӑн пӗрлешӱллӗ ӑс-хакӑл тытӑмӗ пулать тесе ӑнлантарас̧с̧ӗ. Ку тытӑм специалиста професси ме̌н иккенне ӑнланса илме пулӑшать, суйласа илнӗ професси с̧ул-йӗрӗн содержанине, вӑл шутра вӗрнӱпе професси хакне, тӗрӗс пӑхма пулӑшать. ППО тытӑмӗнче когнитив, эмоци тата тыткаларӑш компоненчӗсене уйӑрас̧с̧ӗ. С̧ав вӑхӑтрах пулас хӗсмет ӗс̧ӗпе с̧ыхӑннӑ психологӑн ППО содержанийӗн уйрӑмлӑхӗсем професси правилисенчен, профессие суйланӑ чухнехи сӑлтавлавран тата профессие епле хисепленинчен килме пултарас̧с̧ӗ. ППО тӗп функцийӗ 3 тӗрлӗ пулать: шухӑш йӗркелени, шухӑша хакласа улӑштарни тата таврара пурӑнакан с̧ынсемпе хутшӑнни.

Тӗпчев результачӗсем тӑрӑх, хӗсмет ӗс̧ӗпе пурӑнакан пулас психологсен профессипе с̧ыхӑннӑ тавра курӑмӗпе хаклав пултарулӑхне тӗпчемелли моделе тупнӑ. Ӑна опыт с̧ине таяннӑ тӗпчев никӗсне хума та, психологсен професси пӗлтерёшне вӗренӗвӗн расна шайӗнче тӗрӗс хаклама пулӑшакан сӗнӱсене хатӗрленӗ чухне те шута илме юрать.

Tӗп сӑмахсем: хӗсмет ӗс̧ӗ, профессие тӗрӗс хаклама пулӑшакан тавра курӑм, хӗсмет ӗс̧ӗпе пурӑнакан психолог.

Цитатӑлама: Орлова Е.А. Хӗсмет ӗс̧ӗн пулас психологӗсен профессипе пӗлтерӗшлӗх ориентацийӗ аслӑ шкул тапхӑрӗнче йӗркеленни / Е.А. Орлова, Ю.Л. Гребенников // Вӗренў аталанӑвӗ. - 2021. - Т. 4, №3. - С. 39-45. DOI:10.31483/r-99347.

\section{Введение}

Целым рядом авторов (Г.С. Абрамова, И.В. Вачков, Ю.Л. Гребенников, И.Б. Гриншпун, Н.И. Гуткина, Е.Е. Данилова, И.В. Дубровина, В.В. Зацепин, А.Г. Лидерс, Марьин М.И., Прихожан А.М., Пряжников Н.С., Толстых Н.Н. и др.) отмечаются «особые требования к личности психолога-профессионала и подчеркивается исключительно высокая значимость качеств личности психолога в успешности деятельности даже в сравнении с другими социономическими профессиями, поскольку собственная личность для психолога является по сути «инструментом» для решения как исследовательских, так и практических задач» $[3 ; 5 ; 7]$.

Белокрылова Г.М. пишет, что «...идет ли речь о психотерапии гуманистического толка или экспериментальном изучении мотивации социального поведения, личностные характеристики психолога обязательно сказываются на результатах и самом способе деятельности» [1].

\section{Методы исследования}

Именно поэтому одним из важнейших направлений профессиональных исследований в области психологии был и остается анализ личности и личностных качеств психолога, в том числе реализация факторов, влияющих на формирование ПЦО психолога на этапе высшего образования.

При этом, с одной стороны еще раз подчеркнем, что современные методики в этой области доказывают, что наиболее эффективная профессиональная деятельность практикующего психолога будет более продук- тивной, если в ее основе будут лежать гуманистические концепции и (или) личностно-ориентированные методики, этические принципы и весь объем общечеловеческих ценностей (Т.И. Артемова, Л.Я. Гозман, И.Б. Котова, Е.Б. Лисовская, В.С. Мерлин, Е.Н. Шиянов и др.).

Однако ряд работ (Г.В. Строй и др.) показывают, что «часто молодые люди, делая выбор в пользу профессионализма психолога, руководствуются при этом установками, характеризующимся тем, что, получив профессиональные психологические знания, навыки и умения, они смогут успешно манипулировать людьми, делая их зависимыми от «токсичной» потребности в психологической помощи, зарабатывая таким образом деньги на» чужих проблемах» [8].

Цитируя А.А. Бодалева, «...профессия психолога предполагает, что овладевший ею человек на познавательном уровне проявит способность капитально ориентироваться в общем, особенно в единичном, характеризующем психику людей, и хорошо знать причины, которые обусловливают тот или иной тип ее развития или появления в ней конкретных изменений. На уровне поведенческо-инструментальном он сумеет с позиции своей профессии найти и осуществить способы успешного решения любой из проблем, характер которых входит в компетенцию психолога. Естественно, что вероятность достижения именно такого результата после обучения молодых людей на психологических факультетах страны будет выше, если овладевший ею человек на уровне мотивационно-эмоциональном будет относиться к другому человеку как высшей ценности» [2]. 
Указанное противоречие настоятельно показывает необходимость смещения акцента в процессе профессиональной подготовке будущих психологов в направлении развития ценностно-смысловой сферы студентов, что подчеркивается в целом ряде работ (И.А. Володарская, Ю.Л. Гребенников, Н.М. Лизунский, В.В. Макаров, И.Ю. Малисова, М.И. Марьин, Н.А. Самойлик, А.В. Серый, Г.В. Строй и др.). Авторы также отмечают, что создание психологом наиболее благоприятных условий для развития личности и осуществления личностных изменений его клиентов особенно необходимо для формирования ценностно-смыслового аспекта будущего профессионального психолога $[3 ; 5 ; 7 ; 8]$.

Как анализ теоретических источников, так и многочисленные примеры из практики показывают внутреннюю неоднородность системы ценностных ориентаций личности в процессе ее движения к вершинам профессионализма. Проведенные исследования (Г.В. Строй и др.) показывают, что “.... ходе обучения в вузе она проходит ряд своеобразных модификаций, переосмысливается в процессе выработки личностной и профессиональной позиции психолога, при этом в данный процесс встраивается осознание этических норм профессиональной деятельности, определяется доминирование соответствующего уровня в индивидуальной системе ценностей» [8].

Однако, как уже говорилось выше, далеко не все молодые специалисты-выпускники вуза - способны изменить «устойчивые» представления об «успешности» человека в окружающем его сегодня мире, способны определить свое положение в этом мире и место выбранной профессии в своей жизни, что приводит к возникновению и даже усугублению рассогласования «эталонной» системы профессиональных ценностей и реальных ценностных ориентаций будущего специалиста.

Это, в то же время, вовсе не отменяет возможности «переосмысливания» ценностных ориентаций личности и изменения профессионально-социальных установок специалистов, обусловленных появлением и осознанием ими новых перспектив собственного профессионального роста и развития. Если же ПЦО личности выпускника вуза продолжают противоречить профессиональной системе этики и этическим принципам деятельности психологов. это может привести к серьезному кризису, который ведет к разочарованию в профессиональной деятельности или к ее деформации, застою или даже редукции.

Таким образом, проблема изучения профессионально-ценностной сферы личности психологов и формирования ПЦО будущих психологов на этапе высшего образования в соответствии с избранным профилем подготовки является сегодня особенно интересной и значимой.

В связи с этим, ряд авторов (В.П. Зинченко, Н.А. Самойлик, Г.В. Строй и др.) отмечают, что «сегодня, к сожалению, пока еще сохраняется ситуация, при которой квалифицированных практических психологов, обладающих «культурным психологическим кодом», значительно меньше тех, кто им не обладает» [8].

Кроме того, «преобладание в содержании подготовки будущих психологов объективной (естественно-на- учной) парадигмы приводит к тому, что часть психологов ориентирована на создание «нового» человека с наперед заданными характеристиками, на создание «идеального» клиента, которым можно легко управлять. Это, конечно, может иметь место, но не относительно человека, а относительно «специалиста», относительно «части личности», подчиненной законам производственного взаимодействия» [8].

Гуманистический же подход - это своего рода альтернатива естественно-научной парадигме, он предполагает общее осознание человека как социального и духовного существа, как субъекта, развивающегося в собственном соответствии с целями и стремлениями, которые в первую очередь связаны со способностью человека управлять собственной жизнью и устремлениями (С.Л. Братченко, Д.А. Леонтьев, Л.А. Петровская и др.).

Таким образом, в настоящее время высшие учебные заведения сталкиваются необходимостью подготовки профессионального психолога, способного к концептуальному мышлению, к раскрытию и выявлению своих профессиональных и личностных возможностей, к рефлексивному управлению собственной профессиональной деятельностью, к изменению своей личности и профессиональной идентичности. Это напрямую связано с модернизацией системы образования, с созданием культурной среды для воспитания и формирования, для ценностной, статусной и деятельностной переориентации психолога.

Необходимо заметить, что процесс формирования системы ценностных ориентации личности имеет поэтапный характер, причем одновременно осуществляется общая периодизация индивидуального развития, при этом наиболее важным и необходимым для формирования ПЦО являются достигнутые уровни психического развития личности (Л. Колберг и др.).

Таким образом, система ПЦО должна органично «вплетаться» в структуру профессионально важных качеств специалистов разного профиля, занимая при этом, конечно, центральное место в виде академических ключевых характеристик психологов служебной деятельности [3,5].

В последние годы рядом авторов (Г.В. Строй и др.) были проведены экспериментальные исследования, направленные на изучение этапов и факторов формирования системы ценностных ориентаций практического психолога в процессе вузовского обучения. В контексте данной работы эти работы представляют особый интерес.

На констатирующем этапе эксперимента с помощью нескольких диагностических методик выявлялись такие показатели, как представления студентов о будущей профессиональной деятельности психолога, а также направленность их системы ценностных ориентаций.

Данные констатирующего эксперимента показали, что «групповая иерархия терминальных и инструментальных ценностей характеризуется наибольшей значимостью ценностей продуктивной и активной деятельной жизни, общественного признания, мате- 
риально обеспеченной жизни, познания, эффективности в делах, образованности и широты взглядов, а наименьшее предпочтение отдается студентами таким ценностям, как жизненная мудрость, счастье других людей, любовь, дружба, честность, независимость, смелость.

Оценка будущими психологами ценностно-смысловых ориентации в профессиональной деятельности показала в целом направленность их личности на самоактуализацию, развитие и творческую самореализацию в будущей профессиональной деятельности, что подтверждается тем, что наиболее предпочитаемыми ценностями для обследуемых являются ценности духовного поиска, самосовершенствования, здоровья, престижа, материальной обеспеченности, творческого поиска, общения и чувства полезности, а наименее значимыми - ценности власти и азарта жизни.

Наконец, называя наиболее привлекательные качества личности, необходимые для профессиональной деятельности психолога, студенты чаще всего называли внимательное отношение к людям, коммуникативную воспитанность, такт, доброту, обаяние, бескорыстие, честность и порядочность, а реже всего - эрудированность, усидчивость, интеллект и т.д.» [8].

Таким образом, результаты исследования Г. В. Строй подтвердили предположение о наличии несоответствия между ПЦО личности будущих психологов и их ценностно-смысловыми профессиональными характеристиками. Если профессиональная система ценностей ориентирована на других людей и их интересы, то в личностной системе ценностей доминируют самооценочные приоритеты, что свидетельствует о недостаточном понимании ценностно-смыслового содержания личности будущего профессионального психолога и ее противоречивости личностно-профессиональному развитию.

В целом можно констатировать, «что система ценностных ориентаций личности будущих практических психологов на начальном этапе обучения представляет собой сложную, внутренне неоднородную и многоуровневую структуру, которая отражает неустойчивость и противоречивость ценностно-смысловой сферы» [8].

В работах А.Н. Мушкировой, Т.А. Ольховой и др. субъектность студентов рассматривается как «ценностно-аксиологическая характеристика личности, проявляющаяся в продуктивности деятельности, в ценностно-смысловой самоорганизации поведения и жизнетворчества студента, независимо от направления выбранной профессиональной специализации» [6, с. 4]. ПЦО определяются авторами как «система устойчивых отношений личности к профессии, к себе, как деятелю профессиональной сферы, служащих смыслообразующим компонентом профессиональной деятельности, определяющим ее личностное и социальное значение» [6].

Также, конечно, представляет интерес позиция А.Н. Мушкировой о том, что «существует детерминантная взаимообусловленность между субъективностью студента и ПЦО, т.е. взаимообуславливающая взаимосвязь, то есть этапы формирования профессиональных ценностных ориентаций и стадии развития субъектности студентов носят взаимообуславливающий и до некоторой степени синхронизируются во времени» [6].

Конечно, данный вопрос может рассматриваться и как дискуссионный, поскольку возможность выделения стадий процесса формирования ПЦО и этапов развития субъектности достаточно условна. Однако, как показывает проведенное авторами исследование, можно выявить некоторые взаимосвязи между этими событиями. Другими словами, есть основания говорить, что «присвоение студентом профессиональных ценностей происходит в период адаптации студентов к образовательной среде вуза, преобразование личности студента на основе профессиональных ценностных ориентаций разворачивается в период ценностного самоопределения, самопроектирование личности в профессии совершается в период ее самореализации» [6].

Охарактеризуем указанные выше этапы (А.Н. Мушкирова) более подробно применительно к студентам, обучающимся на бакалавриате.

На первом этапе высшего образования, который обычно происходит на первом курсе, студентом присваивается нормы профессиональной этики, т.е. в этот период у студентов начинают формироваться ценностные характеристики будущей профессиональной деятельности, а образ себя как профессионального будущего начинает «вырисовываться» в результате их деятельности, а также передаваемых ценностей высшего образования. Будущие специалисты начинают также осваивать профессиональные «эталоны» ответственности и характеристики профессиональных моделей специальной сферы, в основе которых лежат исходные общечеловеческие, профессиональные и личностные ценности. Таким образом, развитие профессионального самосознания у студентов становится возможным путем интернализации (трансляции в рамках программы) профессиональных ценностей, трансформации их в самоценностные инструкции, наполнения «вне» профессиональных ценностей и индивидуальных смыслов положительной эмоциональной «окраской».

На втором этапе, который обычно начинается на втором учебном году, ценность самоопределения студентов по отношению к учебному процессу выступает в «трансформации» личности студента на основе профессионально-ценностного обучения. Важной предпосылкой достижения поставленной цели является формирование у студентов умений эффективно выполнять учебно-познавательную деятельность, развитие их самоопределения и самоконтроля во всех основных видах деятельности (учебно-диагностическая, научно-исследовательская и др.). Усиливается личностно-профессиональная идентификация, направленная на активное развитие у студентов их общей ответственности, развитие навыков саморегуляции в своей деятельности, сознательную подготовку к будущей профессиональной деятельности. Преобладание профессиональных ценностей в ПЦО студентов становится достаточно выраженным.

На этом ценностном этапе самоопределения продолжается процесс «вхождения» студентов в профессию, 
формирования у них образа «я» как профессионального будущего, обретения основ профессионального мастерства, формирования целостного подхода к культуре и профессиональной компетентности.

На старших курсах (третий и четвертый курсы) разворачивается третий этап - этап самопроектирования личности студента в профессии. Самопроектирование личности студента в профессии является особой деятельностью для студентов, поскольку они определяют варианты собственного саморазвития в будущей (и отчасти уже начинающейся) профессиональной деятельности. Самостоятельное проектирование требует разработки индивидуальной программы студента, самостоятельно разработанной в выбранной им академической среде. Старшекурсники характеризуются, как правило, общим формированием культуры и профессиональной компетентности, высокой степенью готовности к осуществлению профессиональной деятельности, установлением иерархической структуры ценностей в рамках ПЦО студента с учетом возрастания представленности в ней профессиональных ценностей.

Именно в этот момент становится возможным говорить о проявлениях субъектности студентов, которые предполагают возможность достижения определенного уровня квалификации и разносторонних вариантов индивидуального развития в системе высшего образования, отражающих его уникальность и своеобразие.

Работы А.Н. Мушкировой также показали, что результат процесса формирования ПЦО студентов вуза определяется комплексом психолого-педагогических факторов.

Первый фактор - это «ориентация образовательного процесса на личностно-профессиональное становление студентов как будущих специалистов, предполагающая:

- включение студентов в различные формы деятельности в рамках образовательного процесса;

- вариативность форм и содержания учебной, внеучебной деятельности, обеспечивающая возможность личностного развития студентов на основе обогащения субъективного опыта и расширения компетентностного поля;

- успешная адаптация студента к вузовскому обучению, развитие его личностных качеств и проявление индивидуальных особенностей в учебно-профессиональной деятельности;

- эффективные формы и методы, способствующие личностно-профессиональному становлению студентов (дискуссии, конференции, учебные и производственные практики, метод проектов, исследовательский метод, компоненты социокультурной деятельности)» [6].

Второй фактор - это «актуализация ценностного (аксиологического) потенциала содержания вузовского образования, под которым понимается социально и личностно детерминированное, фиксированное в педагогической науке представление о социальном опыте, подлежащем усвоению подрастающим поколением» [1; 4]. Для «эффективного личностного развития студентов и формирования у них системы профессиональ- ных ценностных ориентаций необходима интеграция ценностного потенциала дисциплин гуманитарного и социально-экономического, естественнонаучного и профессионального циклов, что обеспечивает расширение горизонтов индивидуального самосознания обучающихся, осознание личностного смысла учения, формирование профессиональных ценностных ориентаций, общекультурных и профессиональных компетенций» [6].

Третий психолого-педагогический фактор - это «субъект-субъектное взаимодействие, под которым в психологической науке понимается определенный характер полноправных партнерских диалогических взаимоотношений, возникающих как между преподавателем и студентом, так и между студентами. Принципиально важной при таком характере взаимоотношений является позиция студента как субъекта учебно-профессиональной деятельности, обладающего способностями и возможностями к инициации и осуществлению самообразования и саморазвития в таких системах, как «Студент - Преподаватель», «Студент - Студент», «Студент - Группа», «Студент - Курс, Факультет, Университет, Внешняя Образовательная Среда» [6].

Авторы выделяют также несколько «функций взаимодействия субъектов образовательного процесса, способствующих формированию профессиональных ценностных ориентаций студентов:

- конструктивная функция, которая проявляется в процессе актуализации профессиональных ценностей в образовательном процессе, их критическом осмыслении и интериоризации;

- организационная функция, которая реализуется через субъект-субъектное взаимодействие преподавателей и студентов, направленное на развитие личностных смыслов и ценностных ориентиров у будущих специалистов;

- коммуникативная функция, которая обеспечивается при реализации индивидуальной, групповой и фронтальной форм учебно-познавательной деятельности студентов и способствует оценке и переоценке профессиональных ценностных ориентаций субъектов образовательного процесса;

- информационно-обучающая функция, которая позволяет «транслировать» профессиональные ценностные ориентации различных слоев населения и социальных групп в плоскость общечеловеческих и профессиональных ценностей» [6].

\section{Результаты}

Выше нами были рассмотрены факторы, влияющие на формирование профессионально-ценностных ориентаций будущих психологов служебной деятельности на этапе вузовского обучения. Вероятно, сами эти факторы можно считать «одинаковыми» для всех вузов, однако, как отмечалось выше, цели и задачи подготовки специалистов, содержание образовательных программ в «ведомственных» и «гражданских» вузах будут различаться, задавая «вектор» личностно-профессионального становления обучающихся [3; 5]. 


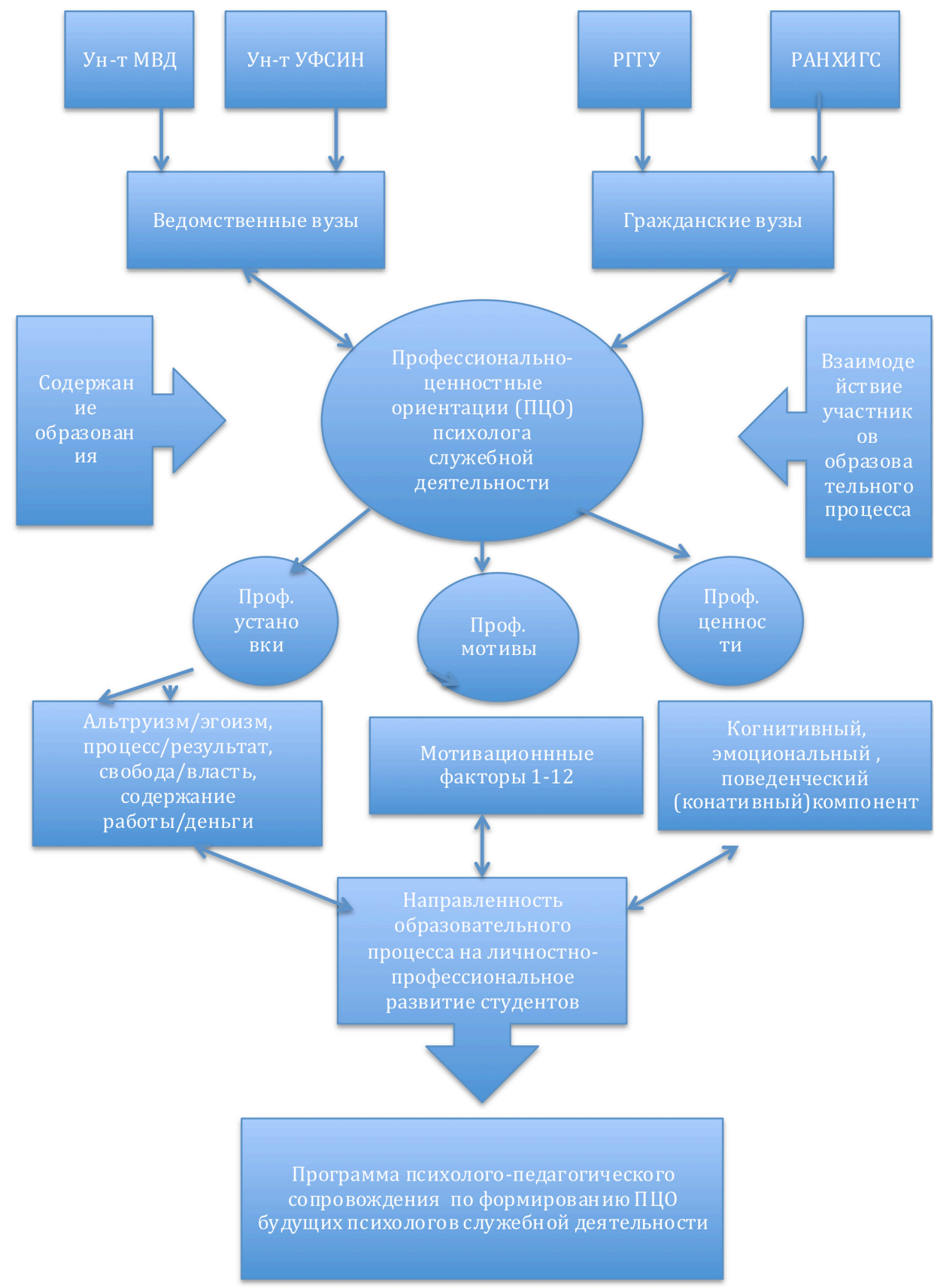

Рис. 1. Модель изучения и формирования профессионально-иенностных ориентащий будущих психологов служебной деятельности

Fig. 1. The Model of Studying and Forming Professional and Value Orientations of Future Psychologists of Professional Activity

Итак, теоретический анализ сущности, содержания и структуры конструкта «Профессионально-ценностные ориентации», а также анализ специфики деятельности и особенностей личности психологов служебной деятельности, преломленный в аспекте их подготовки в условиях вузовского обучения в «ведомственных» и «гражданских» вузах позволил нам разработать модель изучения и формирования профессионально-ценностных ориентаций будущих психологов служебной деятельности (Рис. 1).

Таким образом, можно сделать следующие выводы.

1. Формирование ПЦО будущих психологов служебной деятельности на этапе вузовского образования обусловлено влиянием таких факторов, как направлен- ность образовательного процесса на личностно-профессиональное развитие студентов как будущих специалистов, актуализация этических (аксиологических) аспектов содержания образования и субъект-субъектное взаимодействие участников образовательного процесса.

Предложенная на основе теоретического анализа проблемы модель изучения и формирования профессионально-ценностных ориентаций будущих психологов служебной деятельности может быть положена в основу эмпирического исследования и рекомендаций по формированию и коррекции профессионально-ценностных ориентаций будущих психологов служебной деятельности в разных условиях обучения. 


\section{Список литературы}

1. Белокрылова Г.М. Профессиональное становление студентов-психологов: автореф. дис. ... канд. псих. наук / Г.М. Белокрылова. - М., 1997. - 21 с.

2. Бодалев А.А. Вершина в развитии взрослого человека: характеристики и условия достижения / А.А. Бодалев. - М.: Наука, 1998. - 168 с.

3. Гребенников Ю.Л. Исследование ценностно- смысловых ориентаций сотрудников ФНС / Ю.Л. Гребенников, Е.А. Орлова, Д.И. Куляев // Человеческий капитал. - 2020. - №11 (143). - С. 258-268.

4. Духина Т.Н. Социологический анализ социокультурной составляющей содержательности труда сельского труженика / Т.Н. Духина // Вестник АПК Ставрополья. - 2011. - №3 (3). - С. 87-90.

5. Марьин М.И. Особенности профессионально-ценностных ориентаций будущих психологов служебной деятельности в разных условиях обучения / М.И. Марьин, Ю.Л. Гребенников // Психология XXI века: вызовы, поиски, векторы развития: сб. материалов Всерос. симпозиума психологов (Рязань, 8-9 апр. 2021 г.) с междунар. участием (Россия, Республика Беларусь, Кыргызская Республика, Азербайджанская Республика, Республика Казахстан) / под общ. ред. Д.В. Сочивко. - Рязань: Академия ФСИН России, 2021. - С. 526-530.

6. Мушкирова А.Н. О формировании профессиональных ценностных ориентаций как фактора развития субъектности студентов / А.Н. Мушкирова // Современная педагогика. - 2015. - №2. - С. 44-53 [Электронный ресурс]. - Режим доступа: http://pedagogika.snauka.ru/2015/02/4098 (дата обращения: 06.11.2020).

7. Пименова Е.В. Динамика ценностных ориентаций студентов-психологов в процессе вузовского обучения / Е.В. Пименова // Вестник университета. - 2013. - №13. - С. 300-303.

8. Строй Г.В. Формирование системы ценностных ориентаций будущих практических психологов в процессе обучения: автореф. дис. ... канд. психол. наук / Г.В. Строй. - Ставрополь, 2004. - 28 с.

\section{References}

1. Belokrylova, G.M. (1997). Professional'noe stanovlenie studentov-psikhologov., 21. M.

2. Bodalev, A.A. (1998). Vershina v razvitii vzroslogo cheloveka: kharakteristiki i usloviia dostizheniia., 168. M.: Nauka.

3. Grebennikov, Iu.L., Orlova, E.A., \& Kuliaev, D.I. (2020). Research of Value and Sense Orientations of FTS Employees. Human capital, 11 (143), 258-268.

4. Dukhina, T.N. (2011). Sotsiologicheskii analiz sotsiokul'turnoi sostavliaiushchei soderzhatel'nosti truda sel'skogo truzhenika. Vestnik APK Stavropolia, 3 (3), 87-90.

5. Marin, M.I., \& Grebennikov, Iu.L. (2021). Osobennosti professional'no-tsennostnykh orientatsii budushchikh psikhologov sluzhebnoi deiatel'nosti v raznykh usloviiakh obucheniia. Psikhologiia XXI veka: vyzovy, poiski, vektory razvitiia: sb. materialov Vseros. simpoziuma psikhologov (Riazan, 8-9 apr. 2021 g.) s mezhdunar. uchastiem (Rossiia, Respublika Belarus', Kyrgyzskaia Respublika, Azerbaidzhanskaia Respublika, Respublika Kazakhstan), 526-530. Riazan: Akademiia FSIN Rossii.

6. Mushkirova, A.N. (2015). On the Formation of Professional Value Orientations as the Factor in the Development of Subjectivity of Students. Modern pedagogy, 2, 44-53. Retrieved from http://pedagogika.snauka.ru/2015/02/4098

7. Pimenova, E.V. (2013). Dinamika tsennostnykh orientatsii studentov-psikhologov v protsesse vuzovskogo obucheniia. Vestnik universiteta, 13, 300-303.

8. Stroi, G.V. (2004). Formirovanie sistemy tsennostnykh orientatsii budushchikh prakticheskikh psikhologov v protsesse obucheniia., 28. Stavropol.

Информация об авторах Орлова Елена Александровна д-р психологических наук, профессор, ФГБОУ ВО «Российская академия народного хозяйства и государственной службы при Президенте РФ», Москва, Российская Федерация. Гребенников Юлия Леонидовна канд. психологических наук, доцент, ГОУ ВО МО «Московский государственный областной университет», Мытищи, Московская область, Российская Федерация

\section{Information about the authors}

Elena A. Orlova - doctor of psychological sciences, professor of FSBEI of HE "The Russian Presidential Academy of National Economy and Public Administration",

Moscow, Russian Federation.

Yulia L. Grebennikov - candidate of psychological sciences, associate professor of SEI of HE of MR "Moscow State Regional University",

Mytishchi, Moscow Region, Russian Federation

\begin{abstract}
Авторсём суинчен пӗлтерни Орлова Елена Александровна психологи ӑслӑлӑхӗн д-рӗ, профессор, АВ «Халӑх хус̧алӑхӗпе патшалӑх службин РФ Президенчӗ сууме̌нче есслекен Рас̧с̧ей академийӗ» ФПБВУ, Мускав, Рас̧с̧ей Федерацийӗ.

Гребенников Юлия Леонидовна психологи ӑслӑлӑхӗн к-чӗ, доцент, ВМ АВ «Мускав патшалӑх область университече̌» ПВУ, Мытищи, Мускав облас̧ӗ, Рас̧с̧ей Федерацийӗ я
\end{abstract}

Поступила в редакцию / Received / Редакцие с̧итнӗ 30.08.2021

Принята к публикации / Accepted / Пичетлеме йышӑннӑ 27.09.2021

Опубликована / Published / Пичетленсе тухнӑ 28.09.2021 